\title{
The role of microRNA (miRNA) as a biomarker in HPV and EBV-related cancers
}

\author{
Marcin Koleśnik ${ }^{1, A-D \oplus}$, Ewa Stępień ${ }^{1, A-D \oplus}$, Małgorzata Polz-Dacewicz ${ }^{1, C-F} \oplus$ \\ ${ }^{1}$ Medical University, Lublin, Poland \\ A - Research concept and design, B - Collection and/or assembly of data, C - Data analysis and interpretation, \\ $D$ - Writing the article, E - Critical revision of the article, F - Final approval of the article
}

Koleśnik M, Stępień E, Polz-Dacewicz M. The role of microRNA (miRNA) as a biomarker in HPV and EBV-related cancers. J Pre-Clin Clin Res. 2021; 15(2): 104-110. doi: 10.26444/jpccr/138306

\begin{abstract}
Introduction and objective. Biomarkers are measurable biological indicators of many disease states. Particularly noteworthy are short nucleotide sequences involved in the regulation of many cellular processes. Their level in body fluids constitutes an important biological marker of serious diseases, such as cancer or cardiovascular diseases. For example, different types of microRNA may be used as biomarker in virus-associated cancers. The aim of this article was to review the current knowledge on the miRNAs and their role in viral-related cancers (EBV and HPV). The article reviews information available in journals and on electronic databases.

Brief description of the state of knowledge. A significant part of the world's population hosts at least one of the oncoviruses, but only a small percentage of them undergo a cancerogenesis to which these infectious agents contribute. Interaction between the host cell and viral factors can lead to the origination of a microenvironment favourable to oncogenesis. Cancer arises as a result of dysregulation in many cellular processes, and particularly important are short RNA sequences which regulate the processes that can cause this disease. The varied expression of this ribonucleic acid contributes to many diseases and provides valuable information about health. Importantly, these molecules are differentially expressed in virally-induced cancer. Many publications have confirmed the relationship between the expression of specific types of miRNA and cancers associated with EBV and HPV.

Conclusions. The use of miRNAs as biomarkers of neoplastic diseases associated with EBV and HPV infections may significantly contribute to the reduction of mortality caused by these viruses, and thanks to the development of modern technologies they are an attractive research object.
\end{abstract}

\section{Key words}

cancer, biomarkers, microRNA, HPV, EBV

\section{INTRODUCTION AND OBJECTIVE}

Many biological markers have been applied in cancer diagnosis, therapy or monitoring. Currently, the biomarkers of cancer are mainly proteins present in fluids and tissues, for example, alpha fetoprotein (AFP) and carcinoembryonic antigen (CEA) [1]. Over the past 20 years, a group of small regulatory RNA molecules has aroused great interest and the correlation between expression levels and specific neoplasms has made microRNAs a popular research subject. Moreover, their use as a biological marker may prove to be a breakthrough in terms of diagnostics at all stages of cancer [2-4]. The presence of these molecules in body fluids, such as blood and urine, in addition to transmitting signals to other types of cells, makes them an excellent source of information about the state of the cell $[5,6]$.

\section{STATE OF KNOWLEDGE}

MiRNA - characteristics. Short nucleotide sequences called microRNAs were discovered in the nematode Caenorhabditis elegans, where this non-coding RNA was responsible for binding lin-14 mRNA, which resulted in inhibition of LIN14 protein synthesis [7-9]. Reinhart et al. [10] reported the

Address for correspondence: Marcin Koleśnik, Medical University, Lublin, Poland E-mail: marcinkolesnik@umlub.pl

Received: 21.02.2021; accepted: 31.05.2021; first published: 11.06 .2021 presence of miRNAs in Arabidopsis, confirming that this type of RNA appeared in the common ancestor of plants and animals. It is concluded that miRNAs can make up about $1 \%$ of all genes in mammals and control about half of the genes encoding human proteins $[4,11,12]$. MiRNA precursors are most common in the regions between genes and introns which were previously called 'junk DNA' because their function was unknown. About $98 \%$ of human DNA is untranslated and therefore not convert into a protein product. The ENCODE project found that more than $80 \%$ of the human genome is biologically active, and it is known that some 'junk DNA' is transcribed into non-coding RNA $[2,13]$.

The active and mature miRNA exists in the form of single-stranded RNA associated with the Argonaute family of proteins and forms the fundamental component of RISC (microRNA induced silencing complex). This complex binds to a specific mRNA, usually in the 3'untranslated region, leading to mRNA degradation or translation inhibition. In some cases, the miRNA-Argonaute complex can increase gene expression $[14,15]$. This type of RNA is a fundamental regulator of cellular processes, such as proliferation, differentiation or apoptosis. The expression of this singlestranded molecule varies according to organs and cell types. Both positive and negative regulation of $\mathrm{mRNA}$ can cause serious disease, and it should be noted that hundreds of miRNAs are associated with human disease [2,16, 17], which include cancer, cardiovascular diseases and diseases related to the immune system $[15,18,19]$. 
The currently used biomarkers often do not show sufficiently high sensitivity and specificity. Detection of protein biomarkers is difficult due to the complexity of their structure and the problem of finding accurate detection methods [20]. Therefore, new precise cancer indicators are constantly being searched for. Both DNA and miRNA biomarkers showed increased storage time and appropriate quality [21] and, moreover, the development of new tests requires less time and less cost compared to protein biomarkers. MiRNA levels can be measured using sensitive techniques, including Polymerase Chain Reaction (PCR) or Next Generation Sequencing (NGS), which are constantly being improved. The immunoassay method also deserves special attention in the determination of miRNA because its advantages include high analytical specificity and short waiting time for results [22]. This technique has been used successfully, for example, in the determination of miRNAs in colorectal tumour and surgical margin tissue samples [23]. It should be added that miRNA is stable to most RNA degradation conditions, such as very low or high $\mathrm{pH}[4,24$, 25]. Importantly, the combination of different miRNAs with other biomarkers could be used in the future for precise cancer diagnosis, for example, miR-29a and miR-335 in combination with matrix metalloprotease protein-2 (MMP2) showed better diagnostic efficacy than CEA and tumour antigen 15-3 (CA 15-3) assays used in breast cancer [26]. As a result, miRNAs have wide potential as a biomarker in diagnostics, prognosis and anti-cancer therapy $[4,24,25]$.

MiRNAs and cancer. Cancer is a serious problem for human health worldwide, and constitutes the second most common cause of death, which arises through multiple mutations in genes that stimulate the cell to divide continuously and indefinitely [3]. GLOBOCAN estimates the number of new cancer cases at approximately 19 million, and nearly 10 million deaths in 2020 [27]. The pathogenesis of neoplastic diseases results from disturbed intercellular relations as well as dysfunction of important genes, such as tumour suppressors [3]. The role of miRNA in the development of cancer was studied by Calin et al. [28] on CLL (chronic lymphocytic leukemia). It was then noted that the region of the chromosome that is frequently deleted in CLL lacked the tumour suppressor gene, and instead two microRNA genes were discovered: miR-15a and miR-16-1. Deletion of these two miRNAs increased the proliferation of human and murine B cells by modulating the expression of genes that control cell cycle progression [29]. Moreover, the miR-15/16 cluster has been shown to act as a tumour suppressor which targets the BCL2 oncogene [30]. In 2004, Calin et al. mapped all known microRNA genes and found that many of them reside in regions of the genome involved in chromosomal changes, such as deletion or amplification in a wide variety of human tumours [31]. This non-coding RNA may act as oncogenes or tumour suppressors, and it has been proven that a large proportion of them are involved in chromosomal changes in human cancer.

Analysis of miRNA enables the differentiation between normal and cancer tissue. In addition, it allows distinguishing a specific type of cancer and predicting disease outcome or response to therapy [31]. Deregulation of miRNAs in the tumour can occur as a result of epigenetic changes, including modification of histones or abnormal DNA methylation [32], for example, Saito et al. [33] showed that the use of a DNA methylation inhibitor and a histone deacetylase inhibitor restored expression of miR-127, which targets the BCL6 oncogene. Methylation of specific miRNA genes has downstream cellular consequences. For instance, methylation of the miR-345 gene in colon cancer is associated with inhibition of apoptosis and excessive proliferation of cancer cells [34]. Deregulation of miRNA levels in a tumour may also be the result of structural genetic alterations, including: - chromosomal abnormalities, first found in a study by Calin et al. [28];

- mutations, as the inherited mutations in the primary miR-15 and miR-16 transcripts responsible for decreased miRNA expression in CLL [35];

- single nucleotide polymorphism, which has been described in lung cancer [36].

Overexpression of oncogenic miRNAs can reduce the amount of tumour suppressor gene products, although loss of tumour suppressor miRNA expression may result in an increase in the amount of oncogenic proteins [24]. Modulation of miRNA expression is a promising strategy in the treatment of cancer. Cimmino et al. [30] demonstrated that miR-15a and miR-16-1 can be used in the treatment of BCL2 overexpressing tumours, such as leukemias or lymphomas, taking advantage of the fact that miRNAs reduce oncoprotein levels and consequently induce apoptosis. These miRNAs may also target several oncogene, such as MCL1, CCND1, and WNT3A [37]. Additionally, deregulation of miR-15 and miR-16 has been correlated with a better prognosis in CLL [38], and therefore they have potential for both therapy and disease monitoring.

MiRNA in EBV and HPV-associated cancers. It is estimated that about $12 \%$ of cancers are related to viral infections, with the vast majority in developing countries. It should be noted that the cancerogenesis requires other active factors, such as environmental mutagens, inflammation or immunosuppression; additionally, neoplasm growth caused by viruses usually occurs many years to decades after acute infection. In tumours, viral replication is reduced or absent, and viral genetic material may exist intracellularly as naked nucleic acid in the form of a plasmid, episome, or genome integrated into the host cell [39].

Association of viruses and miRNAs in human tumours may be considered in several ways:

- expressed viral miRNAs promote tumour formation by inhibiting apoptosis, escaping infected cells from host immune surveillance, or modulating signaling [40, 41];

- genome damage due to the integration of foreign DNA affects not only the expression of the genes of tumour suppressor proteins (TS) but also the expression of microRNAs [42, 43];

- use of a viral infection associated with cancer and deregulation of human miRNAs [44, 45].

The Epstein Barr virus (EBV) is historically the first virus in which an miRNA was discovered [46]. This doublestranded herpes virus infects about $90 \%$ of people worldwide, and is found in all major types of lymphoma [47, 48]. EBV is detected in approximately $15 \%$ of diffuse large-B-cell lymphoma (DLBCL) cases [49]. MiRNA profiling by Imig et al. [49] showed that miR-424, -223, -199a-3p, -199a-5p, $-27 b,-378,-26 b,-23 a,-23 b$ were increased, and miR-155, $-20 b,-221,-151-3 p,-222,-29 b / c,-106 a$ were reduced by more 
than 2-fold due to EBV infection of DLBCL. Increased levels of miR-21 have been associated with CLL, DLBCL and acute myeloid leukaemia [50]. Additionally, deregulated miR-21 expression is specific to many other cancers, including glioblastoma, lung cancer, squamous cell carcinoma, and breast cancer [51]. Rosato et al. [51] performed miRNA profiling of virus-infected and EBNA2 (Epstein-Barr virus nuclear antigen 2)-transfected U2932 DLBCL cell lines. MiR21 has been shown to be positively regulated by this viral protein, confirming that EBNA2 can contribute to induced $\mathrm{B}$ cell transformation by altering miRNA expression.

Another example of lymphoma associated with EBV infection is Hodgkin's lymphoma [49]. Jones et al. used quantitative real-time PCR (qRT-PCR) to study plasma miRNA levels of classical Hodgkin's lymphoma patients, compared to healthy participants. Elevated levels of miR21 along with miR-494 and miR-1973 have been reported in cancer patients. It should be noted that these miRNAs returned to normal after disease remission, but only miR-494 and miR-1973 reflected a temporary response to therapy. This allowed the disease response to the therapy to be indicated [52].

EBV is also associated with $\mathrm{NK}$ (natural killer) cell leukemia because it regulates the development of the NK cells from which this kind of cancer is derived. Infections caused by EBV result in immortalization of the lymphoid cells and may also contribute to the elevation of miRNA levels in biological fluids [43].

An oncogenic virus which, unlike EBV, does not encode viral miRNAs, is the small human papillomavirus (HPV) which exists as a spherical episome in cells and contains a double strand DNA. It can be linearized and occasionally integrated into the host genome, which is the case with the common cervical cancer $[32,53]$. The oncogenic effect of this virus is manifested by a change in gene expression [54]. A significant number of miRNAs have been shown to be located close to HPV integration sites, and miRNA genes are possible targets for genome changes induced by HPV integration into the host genome [31]. Many studies have revealed that some families of this type of RNA may be involved in the pathogenesis of HPV-related cancer (e.g. miR-15a, miR-16, miR-195, miR-497, miR-143 or miR-145). HPV deregulates these miRNAs through interactions in the viral oncoprotein pathways, which can lead, e.g. to inhibition of cell cycle arrest, and consequently contribute to carcinogenesis [55].

The HPV genome comprises six non-structural genes and two structural genes. Oncogenes can be distinguished among the first of these and include E6 and E7 [56]. Moreover, recent publications also show the involvement of the E5 gene as an oncogene $[57,58]$, which are committed in the HPV-related transformation, and target miRNAs associated with tumour progression or suppression. For example, the E6 and E7 genes increase the amount of oncogenic miRNA-21, which negatively affects the expression of the tumour suppressor gene PTEN (phosphatase and tensin homolog) $[56,59]$. Additionally, the expression of the E5, E6 and E7 genes in cervical cancer cell lines ( $\mathrm{SiHa}, \mathrm{CaSki}$ ) has led to a reduction in the expression of some miRNAs that inhibit tumorigenesis, such as miRNA-22, miRNA-450 or miRNA-203 [60-62].

It is estimated that about one-fifth of oropharyngeal tumours are caused by HPV [45]. Variable amounts of miRNAs were observed in HPV-positive HNCSCC (head and neck squamous cell carcinoma) and the same tumour cell lines. Diversified expression of miRNAs has been reported in HPV-positive and HPV-negative samples. This suggests that altered miRNA expression may contribute to oncogenesis [44, 63, 64]. MiR-9 has been shown to be constantly detected in HPV positive HNSCC subgroups, and rarely in HPV negative HNSCC subgroups. This indicates the specificity of miR-9 for HPV-associated HNSCC. Due to the presence of HPV, HNSCC is divided into two groups: HPV positive with a better prognosis and HPV negative tumours with a worse prognosis [65]. Bersani et al. [66] demonstrated miR-155 overexpression in tonsillar and base of tongue cancer and linked it to HPV infection and improved survival. In contrast, low miR-185 expression was associated with negative HPV and decreased survival. Examples of miRNAs that may be used as biomarkers in the prognosis or diagnosis of cancers related to EBV and HPV infections are presented in Table 1.

Table 1. MicroRNAs in neoplasms associated with HPV and EBV infection

\begin{tabular}{|c|c|c|c|c|}
\hline $\begin{array}{l}\text { Oncogenic } \\
\text { virus }\end{array}$ & $\begin{array}{l}\text { Type of } \\
\text { cancer }\end{array}$ & $\begin{array}{c}\text { Upregulated } \\
\text { miRNAs }\end{array}$ & $\begin{array}{c}\text { Downregulated } \\
\text { miRNAs }\end{array}$ & References \\
\hline \multirow[t]{2}{*}{ HPV } & $\begin{array}{l}\text { Head and } \\
\text { neck cancer }\end{array}$ & $\begin{array}{c}\text { miR-9; miR-16; } \\
\text { miR-18a; miR-21; } \\
\text { miR-31; miR-33; } \\
\text { miR-363; miR-497 }\end{array}$ & $\begin{array}{l}\text { miR-29a; miR-31; } \\
\text { miR-139-3p; miR- } \\
\text { 142-5p; miR-143; } \\
\text { miR-145; miR-181a; } \\
\text { miR-181b; miR-195; } \\
\text { miR-221; miR-222 }\end{array}$ & $\begin{array}{c}{[55,} \\
67-70]\end{array}$ \\
\hline & $\begin{array}{l}\text { Cervical } \\
\text { cancer }\end{array}$ & $\begin{array}{c}\text { miR-10a; miR-15b; } \\
\text { miR-16; miR-21; } \\
\text { miR-31; miR-127; } \\
\text { miR-132; miR-133b; } \\
\text { miR-145; miR-155; } \\
\text { miR-214 }\end{array}$ & $\begin{array}{c}\text { miR-23b; miR-26a; } \\
\text { miR-29a; miR-34a; } \\
\text { miR-99a/b; miR- } \\
\text { 133a; miR-145 }\end{array}$ & [71-81] \\
\hline \multirow[t]{2}{*}{ EBV } & $\begin{array}{c}\text { Burkitt's } \\
\text { lymphoma }\end{array}$ & miR-127 & miR-28 & {$[82,83]$} \\
\hline & $\begin{array}{l}\text { Head and } \\
\text { neck cancer }\end{array}$ & $\begin{array}{l}\text { miR-31; miR-155; } \\
\text { miR-221/222 }\end{array}$ & miR-134, miR-204 & [84-88] \\
\hline
\end{tabular}

Both HPV and EBV infections are associated with oral squamous cell carcinoma (OSCC), which accounts for approximately $95 \%$ of oral cancer cases, causing approximately 177,000 deaths annually, and late diagnosis is a significant problem in this case [89]. Despite the fact that the oral cavity can be readily to examined, most tumours are diagnosed in the late stage, which reduces the survival rate of patients [90]. The markers of solid tumours used so far, such as carcinoembryonic antigen or carcinoantigen 19-9, have not shown sufficiently high sensitivity and specificity in the effective diagnosis of all oral cancers $[91,92]$. It is known that some miRNAs are specifically associated with the presence of neoplasms, even in the early stages, which is important for the diagnosis of this neoplasm [93]. Increasing expression of miR-21 is associated with low survival in head and neck cancer patients [94]. This type of miRNA is also of interest due to the location of the miR-21 gene close to the HPV integration site [95], and creates an interesting link between cancers caused by these viruses and miR-21. Additionally, miR-223, miR-26a and miR-126 have been shown to be upregulated in oral cancer patients. Interestingly, a higher level of biomarker was found in healthy tissue adjacent to the tumour tissue compared to tumour tissue from patients with oral cancer [43, 89, 96, 97].

In a study by Yan et al., seven OSCC-related miRNAs were identified, three of which (miR-21, miR-31, miR-338) showed upregulation, while the others (miR-125b, miR-133a, miR-133b, miR-139) were downregulated [98]. Moreover, 
Petronacci et al. [99] found altered expression of miR-497-5p and miR-4417 in OSCC samples and associated deregulated levels of these miRNAs with the proteoglycan pathway in cancer. These studies indicate the possibility of using miRNAs as biomarkers in the prognosis and diagnosis of head and neck cancers, such as OSCC. It should be noted that from the perspective of clinical use, further studies are required to confirm the sufficient sensitivity and specificity of miRNAs.

To date, several clinical trials of miRNA in cancer have been registered in the clinicaltrials.gov database. For example, the study entitled: MicroRNA Markers in Head and Neck Cancers (NCT04305366) investigates whether miRNA markers present in the body fluids of patients could provide prognostic or diagnostic clinical relevance in the treatment of cancer. Another example is a study that aimed to identify haematological malignancies, and predict treatment using microRNA as a diagnostic tool (NCT02791217). It should be noted that a large part of the research on these biomarkers is at the stage of collecting participants. The results, however, may provide important information on the use of specific miRNAs as biological markers in the future.

EBV-encoded miRNAs. Currently, many oncoviruses encoding miRNAs have been discovered, for example, the role of viral miRNAs in the pathogenesis of cancers associated with Kaposi's sarcoma virus has been shown [100]. EBV is also a virus encoding miRNAs. EBV encodes 44 BamHI-A rightward fragment-derived miRNAs (BART) and 4 BamHI-H rightward fragment 1-derived miRNAs (BHRF1) [101]. Expression of BHRF1 miRNAs depends on the type of viral latency, while BART miRNAs are expressed with all forms of latency [102]. EBV-encoded miRNAs are involved in inhibiting apoptosis, promoting B-cell survival, and avoiding recognition by the immune system [103]. Furthermore, it regulates viral mRNA transcripts [44].

Vereide et al. [104], using luciferase reporter assay, investigated whether caspase-3 is the target of BART miRNAs. Removal of the BART miRNA increased the level of caspase 3 protein, and reintroducing this miRNA decreased its amount. The results proved that EBV's miRNAs support Burkitt's lymphoma cells in the absence of other oncogenes by inhibiting apoptosis, and viral miRNAs promoted the transformation of primary B cells [104, 105].

Several functions of viral RNA in nasopharyngeal cancer have been confirmed in research $[41-43,45]$. In this neoplasm, EBV-encoded miR-BART is highly expressed and contributes to the development of this disease by targeting various cellular or viral genes [106]. Overall, miRNAs are encoded by both the host and EBV and play a crucial role in various stages of epithelial cell carcinoma [32]. It has been shown that EBV-miRNAs, BART5-5p, BART7-3p, BART9-3p, and BART14-3p can inhibit the expression of the ataxia telangiectasia mutated (ATM) gene, which has a key role in DNA damage response and repair [106]. Another study has also demonstrated that miR-BART1-5p, $3,4,5,6,7,8,10$, and $18-3$ p were highly expressed in NPC tissues, and genomic pathway analysis showed that these EBV miRNAs target pathways signal transforming growth factor $\beta$ (TGF- $\beta$ ) and Wnt, which are involved in reprogramming the bioenergy of cancer cells [107]. Moreover, miR-BART1 is responsible for the migration, invasiveness and metastasis of NPC cells by suppressing PTEN. It should be emphasized that abnormal EBV miRNA expression may contribute to metabolic abnormalities and oncogenesis in EBV infected cells by disrupting the balance of various signaling pathways $[108,109]$. Interestingly, the levels of EBV miRNA expressed in tumour biopsies were higher than in EBV cell lines, indicating that miRNAs may have more genomic targets regulated in vivo than in cell culture [110].

\section{CONCLUSIONS}

The prospect of using non-invasive molecules found in biological fluids is very promising. MiRNAs such as miR21 may be used in the future on a large scale in the diagnosis and treatment of cancer diseases associated with viral infections. Currently, several miRNA-based drugs are at different stages of clinical studies, and modern molecular advances in biology, such as next-generation sequencing, can significantly contribute to faster discovery in these noncoding RNAs. The findings in the field of miRNA expression levels with viral associated neoplasms could provide much relevant information regarding the regulation of oncogenesis; however, knowledge and research about these short nucleotide sequences has to be constantly expanded.

\section{REFERENCES}

1.Hu B, Niu X, Cheng L, et al. Discovering cancer biomarkers from clinical samples by protein microarrays. PROTEOMICS - Clin Appl. 2015; 9(1-2): 98-110. doi: https://doi.org/10.1002/prca.201400094

2. Romano G, Veneziano D, Acunzo M, Croce CM. Small non-coding RNA and cancer. Carcinogenesis. 2017; 38(5): 485-491. doi: 10.1093/ carcin/bgx026

3. Hassanpour SH, Dehghani M. Review of cancer from perspective of molecular. J Cancer Res Pract. 2017; 4(4): 127-129. doi: 10.1016/j. jcrpr.2017.07.001

4. Negrini M, Nicoloso MS, Calin GA. MicroRNAs and cancer-new paradigms in molecular oncology. Curr Opin Cell Biol. 2009; 21(3): 470-479. doi: 10.1016/j.ceb.2009.03.002

5. Danarto R, Astuti I, Department of Pharmacology, Universitas Gadjah Mada School of Medicine, Yogyakarta, Indonesia, et al. Urine miR-21$5 \mathrm{p}$ and $\mathrm{miR}-200 \mathrm{c}-3 \mathrm{p}$ as potential non-invasive biomarkers in patients with prostate cancer. Türk Ürol DergisiTurkish J Urol. 2020; 46(1): 26-30. doi: 10.5152/tud.2019.19163

6. Koppers-Lalic D, Hackenberg M, Menezes R de, et al. Non-invasive prostate cancer detection by measuring miRNA variants (isomiRs) in urine extracellular vesicles. Oncotarget. 2016; 7(16): 22566-22578. doi: 10.18632/oncotarget.8124

7. Lee RC, Feinbaum RL, Ambros V. The C. elegans heterochronic gene lin-4 encodes small RNAs with antisense complementarity to lin-14. Cell. 1993; 75(5): 843-854. doi: 10.1016/0092-8674(93)90529-Y

8. Reinhart BJ, Slack FJ, Basson M, et al. The 21-nucleotide let-7 RNA regulates developmental timing in Caenorhabditis elegans. Nature. 2000; 403(6772): 901-906. doi: 10.1038/35002607

9. Wightman B, Ha I, Ruvkun G. Posttranscriptional regulation of the heterochronic gene lin-14 by lin- 4 mediates temporal pattern formation in C. elegans. Cell. 1993; 75(5): 855-862. doi: 10.1016/00928674(93)90530-4

10. Reinhart BJ, Weinstein EG, Rhoades MW, Bartel B, Bartel DP. MicroRNAs in plants. Genes Dev. 2002; 16(13): 1616-1626. doi: 10.1101/ gad. 1004402

11. Cai Y, Yu X, Hu S, Yu J. A Brief Review on the Mechanisms of miRNA Regulation. Genomics Proteomics Bioinformatics. 2009; 7(4): 147-154. doi: 10.1016/S1672-0229(08)60044-3

12.Zhou S, Jin J, Wang J, et al. miRNAS in cardiovascular diseases: potential biomarkers, therapeutic targets and challenges. Acta Pharmacol Sin. 2018; 39(7): 1073-1084. doi: 10.1038/aps.2018.30

13. Leigh-Ann M, Paul RM. MicroRNA: Biogenesis, Function and Role in Cancer. Curr Genomics. 2010; 11(7): 537-561. 
14. Panganiban RP, Wang Y, Howrylak J, et al. Circulating microRNAs as biomarkers in patients with allergic rhinitis and asthma. J Allergy Clin Immunol. 2016; 137(5): 1423-1432. doi: 10.1016/j. jaci.2016.01.029

15. Parikh VN, Park J, Nikolic I, et al. Brief Report: Coordinated Modulation of Circulating miR-21 in HIV, HIV-Associated Pulmonary Arterial Hypertension, and HIV/Hepatitis C Virus Coinfection. JAIDS J Acquir Immune Defic Syndr. 2015; 70(3): 236-241. doi: 10.1097/ QAI.0000000000000741

16. Schulte C, Karakas M, Zeller T. microRNAs in cardiovascular disease clinical application. Clin Chem Lab Med CCLM. 2017; 55(5): 687-704. doi: 10.1515/cclm-2016-0576

17. Patel VD, Capra JA. Ancient human miRNAs are more likely to have broad functions and disease associations than young miRNAs. BMC Genomics. 2017; 18(1): 672. doi: 10.1186/s12864-017-4073-Z

18. Migita K, Komori A, Kozuru H, et al. Circulating microRNA Profiles in Patients with Type-1 Autoimmune Hepatitis. PLOS ONE. 2015; 10(11): e0136908. doi: 10.1371/journal.pone.0136908

19. Qu K, Zhang X, Lin T, et al. Circulating miRNA-21-5p as a diagnostic biomarker for pancreatic cancer: evidence from comprehensive miRNA expression profiling analysis and clinical validation. Sci Rep. 2017; 7(1): 1692. doi: 10.1038/s41598-017-01904-Z

20. Condrat CE, Thompson DC, Barbu MG, et al. miRNAs as Biomarkers in Disease: Latest Findings Regarding Their Role in Diagnosis and Prognosis. Cells. 2020; 9(2). doi: 10.3390/cells9020276

21. Rounge TB, Lauritzen M, Langseth H, Enerly E, Lyle R, Gislefoss RE. microRNA Biomarker Discovery and High-Throughput DNA Sequencing Are Possible Using Long-term Archived Serum Samples. Cancer Epidemiol Biomark Prev Publ Am Assoc Cancer Res Cosponsored Am Soc Prev Oncol. 2015; 24(9): 1381-1387. doi: 10.1158/1055-9965.EPI-15-0289

22. Kappel A, Backes C, Huang Y, et al. MicroRNA in vitro diagnostics using immunoassay analyzers. Clin Chem. 2015; 61(4): 600-607. doi: 10.1373/clinchem.2014.232165

23. Dawidowicz M, Kula A, Mielcarska S, et al. miREIA - an immunoassay method in assessment of microRNA levels in tumour tissue-pilot study. The impact of miR-93-5p, miR-142-5p and IFN $\gamma$ on PD-L1 level in colorectal cancer. Acta Biochim Pol. Published online 2020. doi: 10.18388/abp.2020_5533

24. Iorio MV, Croce CM. microRNA involvement in human cancer Carcinogenesis. 2012; 33(6): 1126-1133. doi: 10.1093/carcin/bgs140

25. Wang Q, Ye B, Wang P, Yao F, Zhang C, Yu G. Overview of microRNA199a Regulation in Cancer. Cancer Manag Res. 2019; 11: 10327-10335. doi: 10.2147/CMAR.S231971

26. Ahmed EA, El-Basit SAA, Mohamed MA, Swellam M. Clinical role of MiRNA 29a and MiRNA 335 on breast cancer management: their relevance to MMP2 protein level. Arch Physiol Biochem. 2020; 0(0): 1-8. doi: 10.1080/13813455.2020.1749085

27. Sung H, Ferlay J, Siegel RL, et al. Global cancer statistics 2020 GLOBOCAN estimates of incidence and mortality worldwide for 36 cancers in 185 countries. CA Cancer J Clin. doi: https://doi.org/10.3322/ caac. 21660

28. Calin GA, Dumitru CD, Shimizu M, et al. Frequent deletions and down-regulation of micro- RNA genes miR15 and miR16 at 13q14 in chronic lymphocytic leukemia. Proc Natl Acad Sci. 2002; 99(24): 15524-15529. doi: 10.1073/pnas.242606799

29. Klein U, Lia M, Crespo M, et al. The DLEU2/miR-15a/16-1 cluster controls B cell proliferation and its deletion leads to chronic lymphocytic leukemia. Cancer Cell. 2010; 17(1): 28-40. doi: 10.1016/j. ccr.2009.11.019

30. Cimmino A, Calin GA, Fabbri M, et al. miR-15 and miR-16 induce apoptosis by targeting BCL2. Proc Natl Acad Sci. 2005; 102(39): 13944 13949. doi: 10.1073/pnas.0506654102

31. Calin GA, Sevignani C, Dumitru CD, et al. Human microRNA genes are frequently located at fragile sites and genomic regions involved in cancers. Proc Natl Acad Sci USA. 2004; 101(9): 2999-3004. doi: $10.1073 /$ pnas.0307323101

32. Sannigrahi MK, Sharma R, Singh V, Panda NK, Rattan V, Khullar M. DNA methylation regulated microRNAs in HPV-16-induced head and neck squamous cell carcinoma (HNSCC). Mol Cell Biochem. 2018; 448(1): 321-333. doi: 10.1007/s11010-018-3336-6

33. Saito Y, Liang G, Egger G, et al. Specific activation of microRNA-127 with downregulation of the proto-oncogene BCL6 by chromatinmodifying drugs in human cancer cells. Cancer Cell. 2006; 9(6): 435-443. doi: 10.1016/j.ccr.2006.04.020

34. Tang JT, Wang JL, Du W, et al. MicroRNA 345, a methylation-sensitive microRNA is involved in cell proliferation and invasion in human colorectal cancer. Carcinogenesis. 2011; 32(8): 1207-1215. doi: 10.1093/ carcin/bgr114

35. Raveche ES, Salerno E, Scaglione BJ, et al. Abnormal microRNA-16 locus with synteny to human $13 \mathrm{q} 14$ linked to CLL in NZB mice. Blood. 2007; 109(12): 5079-5086. doi: 10.1182/blood-2007-02-071225

36. Hu Z, Chen J, Tian T, et al. Genetic variants of miRNA sequences and non-small cell lung cancer survival. J Clin Invest. 2008; 118(7): 2600-2608. doi: 10.1172/JCI34934

37. Aqeilan RI, Calin GA, Croce CM. miR-15a and miR-16-1 in cancer: discovery, function and future perspectives. Cell Death Differ. 2010; 17(2): 215-220. doi: 10.1038/cdd.2009.69

38. Calin GA, Ferracin M, Cimmino A, et al. A MicroRNA Signature Associated with Prognosis and Progression in Chronic Lymphocytic Leukemia. N Engl J Med. 2005; 353(17): 1793-1801. doi: 10.1056/ NEJMoa050995

39. Mui UN, Haley CT, Tyring SK. Viral Oncology: Molecular Biology and Pathogenesis. J Clin Med. 2017; 6(12): 111. doi: 10.3390/jcm6120111

40. Chawla JPS, Iyer N, Soodan KS, Sharma A, Khurana SK, Priyadarshni P. Role of miRNA in cancer diagnosis, prognosis, therapy and regulation of its expression by Epstein-Barr virus and human papillomaviruses: With special reference to oral cancer. Oral Oncol. 2015; 51(8): 731-737. doi: 10.1016/j.oraloncology.2015.05.008

41. Shannon-Lowe C, Rickinson A. The Global Landscape of EBVAssociated Tumours. Front Oncol. 2019; 9. doi: 10.3389/fonc.2019.00713

42. Berti FCB, Salviano-Silva A, Beckert HC, de Oliveira KB, Cipolla GA, Malheiros D. From squamous intraepithelial lesions to cervical cancer: Circulating microRNAs as potential biomarkers in cervical carcinogenesis. Biochim Biophys Acta BBA - Rev Cancer. 2019; 1872(2): 188306. doi: 10.1016/j.bbcan.2019.08.001

43. Feng YH, Tsao CJ. Emerging role of microRNA-21 in cancer (Review). Biomed Rep. 2016; 5(4): 395-402. doi: 10.3892/br.2016.747

44. Fiorucci G, Chiantore MV, Mangino G, Romeo G. MicroRNAs in virus-induced tumourigenesis and IFN system. Cytokine Growth Factor Rev. 2015; 26(2): 183-194. doi: 10.1016/j.cytogfr.2014.11.002

45. Snoek BC, Babion I, Koppers-Lalic D, Pegtel DM, Steenbergen RD. Altered microRNA processing proteins in HPV-induced cancers Curr Opin Virol. 2019; 39: 23-32. doi: 10.1016/j.coviro.2019.07.002

46. Pfeffer S, Zavolan M, Grässer FA, et al. Identification of VirusEncoded MicroRNAs. Science. 2004; 304(5671): 734-736. doi: 10.1126/ science. 1096781

47. Iizasa H, Kim H, Kartika AV, Kanehiro Y, Yoshiyama H. Role of Viral and Host microRNAs in Immune Regulation of Epstein-Barr Virus-Associated Diseases. Front Immunol. 2020; 11. doi: 10.3389/ fimmu.2020.00367

48. Koleśnik M, Dworzańska A, Polz-Dacewicz M. Wirus Epsteina-Barr w wybranych chorobach nowotworowych. Postępy Biochem. 2020; 66(4): 385-389. doi: 10.18388/pb.2020_364

49. Imig J, Motsch N, Zhu JY, et al. microRNA profiling in Epstein-Barr virus-associated B-cell lymphoma. Nucleic Acids Res. 2011; 39(5): 1880-1893. doi: 10.1093/nar/gkq1043

50. Medina PP, Nolde M, Slack FJ. OncomiR addiction in an in vivo model of microRNA-21-induced pre-B-cell lymphoma. Nature. 2010; 467(7311): 86-90. doi: 10.1038/nature09284

51. Rosato P, Anastasiadou E, Garg N, et al. Differential regulation of miR21 and miR-146a by Epstein-Barr virus-encoded EBNA2. Leukemia. 2012; 26(11): 2343-2352. doi: 10.1038/leu.2012.108

52. Jones K, Nourse JP, Keane C, Bhatnagar A, Gandhi MK. Plasma microRNA are disease response biomarkers in classical Hodgkin lymphoma. Clin Cancer Res Off J Am Assoc Cancer Res. 2014; 20(1): 253-264. doi: 10.1158/1078-0432.CCR-13-1024

53. Takeuchi T, Kawasaki H, Luce A, et al. Insight toward the MicroRNA Profiling of Laryngeal Cancers: Biological Role and Clinical Impact. Int J Mol Sci. 2020; 21(10): 3693. doi: 10.3390/ijms21103693

54. Chang SS, Jiang WW, Smith I, et al. MicroRNA alterations in head and neck squamous cell carcinoma. Int J Cancer. 2008; 123(12): 2791-2797. doi: $10.1002 /$ ijc. 23831

55. Lajer CB, Garnæs E, Friis-Hansen L, et al. The role of miRNAs in human papilloma virus (HPV)-associated cancers: bridging between HPV-related head and neck cancer and cervical cancer. Br J Cancer. 2012; 106(9): 1526-1534. doi: 10.1038/bjc.2012.109

56. Park S, Eom K, Kim J, et al. MiR-9, miR-21, and miR-155 as potential biomarkers for HPV positive and negative cervical cancer. BMC Cancer. 2017; 17(1): 658. doi: 10.1186/s12885-017-3642-5

57. Estêvão D, Costa NR, Gil da Costa RM, Medeiros R. Hallmarks of HPV carcinogenesis: The role of E6, E7 and E5 oncoproteins in cellular malignancy. Biochim Biophys Acta BBA - Gene Regul Mech. 2019; 1862(2): 153-162. doi: 10.1016/j.bbagrm.2019.01.001 
58. GuptaS, KumarP,Das BC.HPV:Molecularpathwaysand targets. CurrProbl Cancer. 2018; 42(2): 161-174. doi:10.1016/j.currproblcancer.2018.03.003

59. Iliopoulos D, Jaeger SA, Hirsch HA, Bulyk ML, Struhl K. STAT3 activation of miR-21 and miR-181b-1 via PTEN and CYLD are part of the epigenetic switch linking inflammation to cancer. Mol Cell. 2010; 39(4): 493-506. doi: 10.1016/j.molcel.2010.07.023

60.Zheng ZM, Wang X. Regulation of cellular miRNA expression by human papillomaviruses. Biochim Biophys Acta. 2011; 1809(11-12): 668-677. doi: 10.1016/j.bbagrm.2011.05.005

61. Wang X, Wang HK, Li Y, et al. microRNAs are biomarkers of oncogenic human papillomavirus infections. Proc Natl Acad Sci. 2014; 111(11): 4262-4267. doi: 10.1073/pnas.1401430111

62. Wongjampa W, Ekalaksananan T, Chopjitt P, et al. Suppression of miR22 , a tumour suppressor in cervical cancer, by human papillomavirus 16 E6 via a p53/miR-22/HDAC6 pathway. PloS One. 2018; 13(10): e0206644. doi: 10.1371/journal.pone.0206644

63. Pinatti LM, Walline HM, Carey TE. Human Papillomavirus Genome Integration and Head and Neck Cancer. J Dent Res. 2018; 97(6): 691700. doi: 10.1177/0022034517744213

64. Chang Y, Moore PS, Weiss RA. Human oncogenic viruses: nature and discovery. Philos Trans R Soc B Biol Sci. 2017; 372(1732): 20160264. doi: 10.1098/rstb.2016.0264

65. Božinović K, Sabol I, Dediol E, et al. Genome-wide miRNA profiling reinforces the importance of miR-9 in human papillomavirus associated oral and oropharyngeal head and neck cancer. Sci Rep. 2019; 9(1): 2306. doi: 10.1038/s41598-019-38797-z

66. Bersani C, Mints M, Tertipis N, et al. MicroRNA-155, -185 and -193b as biomarkers in human papillomavirus positive and negative tonsillar and base of tongue squamous cell carcinoma. Oral Oncol. 2018; 82: 8-16. doi: 10.1016/j.oraloncology.2018.04.021

67. Lu E, Su J, Zeng W, Zhang C. Enhanced miR-9 promotes laryngocarcinoma cell survival via down-regulating PTEN. Biomed Pharmacother Biomedecine Pharmacother. 2016; 84: 608-613. doi: 10.1016/j. biopha.2016.09.047

68. Liu M, Wu H, Liu T, et al. Regulation of the cell cycle gene, BTG2, by miR-21 in human laryngeal carcinoma. Cell Res. 2009; 19(7): 828-837. doi: $10.1038 / \mathrm{cr} .2009 .72$

69. Wald AI, Hoskins EE, Wells SI, Ferris RL, Khan SA. Alteration of microRNA profiles in squamous cell carcinoma of the head and neck cell lines by human papillomavirus. Head Neck. 2011; 33(4): 504-512. doi: $10.1002 /$ hed. 21475

70. Bufalino A, Cervigne NK, de Oliveira CE, et al. Low miR-143/miR-145 Cluster Levels Induce Activin A Overexpression in Oral Squamous Cell Carcinomas, Which Contributes to Poor Prognosis. PloS One. 2015; 10(8): e0136599. doi: 10.1371/journal.pone.0136599

71. Wang N, Zhou Y, Zheng L, Li H. MiR-31 is an independent prognostic factor and functions as an oncomir in cervical cancer via targeting ARID1A. Gynecol Oncol. 2014; 134(1): 129-137. doi: 10.1016/j. ygyno.2014.04.047

72.Long MJ, Wu FX, Li P, Liu M, Li X, Tang H. MicroRNA-10a targets CHL1 and promotes cell growth, migration and invasion in human cervical cancer cells. Cancer Lett. 2012; 324(2): 186-196. doi: 10.1016/j. canlet.2012.05.022

73. Wang X, Tang S, Le SY, et al. Aberrant Expression of Oncogenic and Tumour-Suppressive MicroRNAs in Cervical Cancer Is Required for Cancer Cell Growth. PLOS ONE. 2008; 3(7): e2557. doi: 10.1371/ journal.pone.0002557

74. You W, Wang Y, Zheng J. Plasma miR-127 and miR-218 Might Serve as Potential Biomarkers for Cervical Cancer. Reprod Sci. 2015; 22(8): 1037-1041. doi: 10.1177/1933719115570902

75. Campos-Viguri GE, Jiménez-Wences H, Peralta-Zaragoza O, et al. miR-23b as a potential tumour suppressor and its regulation by DNA methylation in cervical cancer. Infect Agent Cancer. 2015; 10(1): 42. doi: 10.1186/s13027-015-0037-6

76. Dong J, Sui L, Wang Q, Chen M, Sun H. MicroRNA-26a inhibits cell proliferation and invasion of cervical cancer cells by targeting protein tyrosine phosphatase type IVA 1. Mol Med Rep. 2014; 10(3): 1426-1432. doi: $10.3892 / \mathrm{mmr} .2014 .2335$

77. Yamamoto N, Kinoshita T, Nohata N, et al. Tumour-suppressive microRNA-29a inhibits cancer cell migration and invasion via targeting HSP47 in cervical squamous cell carcinoma. Int J Oncol. 2013; 43(6): 1855-1863. doi: 10.3892/ijo.2013.2145

78. Geng D, Song X, Ning F, Song Q, Yin H. MiR-34a Inhibits Viability and Invasion of Human Papillomavirus-Positive Cervical Cancer Cells by Targeting E2F3 and Regulating Survivin. Int J Gynecol Cancer Off J Int Gynecol Cancer Soc. 2015; 25(4): 707-713. doi: 10.1097/ IGC.0000000000000399
79. Wang L, Chang L, Li Z, et al. miR-99a and -99b inhibit cervical cancer cell proliferation and invasion by targeting mTOR signaling pathway. Med Oncol Northwood Lond Engl. 2014; 31(5): 934. doi: 10.1007/ s12032-014-0934-3

80. Song X, Shi B, Huang K, Zhang W. miR-133a inhibits cervical cancer growth by targeting EGFR. Oncol Rep. 2015; 34(3): 1573-1580. doi: 10.3892/or.2015.4101

81.Zhou X, Yue Y, Wang R, Gong B, Duan Z. MicroRNA-145 inhibits tumourigenesis and invasion of cervical cancer stem cells. Int J Oncol. 2017; 50 (3): 853-862. doi: 10.3892/ijo.2017.3857

82. Onnis A, Navari M, Antonicelli G, et al. Epstein-Barr nuclear antigen 1 induces expression of the cellular microRNA hsa-miR-127 and impairing B-cell differentiation in EBV-infected memory B cells. New insights into the pathogenesis of Burkitt lymphoma. Blood Cancer J. 2012; 2: e84. doi: 10.1038/bcj.2012.29

83. Bartolomé-Izquierdo N, de Yébenes VG, Álvarez-Prado AF, et al. miR28 regulates the germinal center reaction and blocks tumour growth in preclinical models of non-Hodgkin lymphoma. Blood. 2017; 129(17): 2408-2419. doi: 10.1182/blood-2016-08-731166

84. Ni YH, Huang XF, Wang ZY, et al. Upregulation of a potential prognostic biomarker, miR-155, enhances cell proliferation in patients with oral squamous cell carcinoma. Oral Surg Oral Med Oral Pathol Oral Radiol. 2014; 117(2): 227-233. doi: 10.1016/j. oooo.2013.10.017

85. Yang CJ, Shen WG, Liu CJ, et al. miR-221 and miR-222 expression increased the growth and tumourigenesis of oral carcinoma cells. J Oral Pathol Med. 2011; 40(7): 560-566. doi: https://doi.org/10.1111/j.16000714.2010.01005.x

86. Salazar C, Nagadia R, Pandit P, et al. A novel saliva-based microRNA biomarker panel to detect head and neck cancers. Cell Oncol Dordr. 2014; 37(5): 331-338. doi: 10.1007/s13402-014-0188-2

87. Lucas Grzelczyk W, Szemraj J, Kwiatkowska S, Józefowicz-Korczyńska M. Serum expression of selected miRNAs in patients with laryngeal squamous cell carcinoma (LSCC). Diagn Pathol. 2019; 14(1): 49. doi: 10.1186/s13000-019-0823-3

88. Yu CC, Chen PN, Peng CY, Yu CH, Chou MY. Suppression of miR-204 enables oral squamous cell carcinomas to promote cancer stemness, EMT traits, and lymph node metastasis. Oncotarget. 2016; 7(15): 20180-20192. doi: 10.18632/oncotarget.7745

89. Falzone L, Lupo G, La Rosa GRM, et al. Identification of Novel MicroRNAs and Their Diagnostic and Prognostic Significance in Oral Cancer. Cancers. 2019; 11(5): 610. doi: 10.3390/cancers11050610

90. Akbulut N, Oztas B, Kursun S, Evirgen S. Delayed diagnosis of oral squamous cell carcinoma: a case series. J Med Case Reports. 2011; 5(1): 291. doi: 10.1186/1752-1947-5-291

91. Zheng J, Sun L, Yuan W, et al. Clinical value of Naa10p and CEA levels in saliva and serum for diagnosis of oral squamous cell carcinoma. J Oral Pathol Med Off Publ Int Assoc Oral Pathol Am Acad Oral Pathol. 2018; 47(9): 830-835. doi: 10.1111/jop.12767

92. Yuan C, Yang K, Tang H, Chen D. Diagnostic values of serum tumour markers Cyfra21-1, SCCAg, ferritin, CEA, CA19-9, and AFP in oral/ oropharyngeal squamous cell carcinoma. OncoTargets Ther. 2016; 9: 3381-3386. doi: 10.2147/OTT.S105672

93. Falzone L, Romano GL, Salemi R, et al. Prognostic significance of deregulated microRNAs in uveal melanomas. Mol Med Rep. 2019; 19(4): 2599-2610. doi: 10.3892/mmr.2019.9949

94. Fu X, Han Y, Wu Y, et al. Prognostic role of microRNA-21 in various carcinomas: a systematic review and meta-analysis. Eur J Clin Invest. 2011; 41(11): 1245-1253. doi: 10.1111/j.1365-2362.2011.02535.x

95. Thorland EC, Myers SL, Gostout BS, Smith DI. Common fragile sites are preferential targets for HPV16 integrations in cervical tumours. Oncogene. 2003; 22(8): 1225-1237. doi: 10.1038/sj.onc.1206170

96. Pereira CM, Sehnem D, da Fonseca EO, et al. miRNAs: Important Targets for Oral Cancer Pain Research. BioMed Res Int. 2017; 2017: e4043516. doi: 10.1155/2017/4043516

97. Tachibana H, Sho R, Takeda Y, et al. Circulating miR-223 in Oral Cancer: Its Potential as a Novel Diagnostic Biomarker and Therapeutic Target. PLoS ONE. 2016; 11(7). doi: 10.1371/journal. pone. 0159693

98. Yan ZY, Luo ZQ, Zhang LJ, Li J, Liu JQ. Integrated Analysis and MicroRNA Expression Profiling Identified Seven miRNAs Associated With Progression of Oral Squamous Cell Carcinoma. J Cell Physiol. 2017; 232(8): 2178-2185. doi: 10.1002/jcp. 25728

99. Chamorro Petronacci CM, Pérez-Sayáns M, Padín Iruegas ME, et al. miRNAs expression of oral squamous cell carcinoma patients: Validation of two putative biomarkers. Medicine (Baltimore). 2019; 98(13): e14922. doi: 10.1097/MD.0000000000014922 
100. Wu XJ, Pu XM, Zhao ZF, et al. The expression profiles of microRNAs in Kaposi's sarcoma. Tumour Biol. 2015; 36(1): 437-446. doi: 10.1007/ s13277-014-2626-1

101. Kim H, Iizasa H, Kanehiro Y, Fekadu S, Yoshiyama H. Herpesviral microRNAs in Cellular Metabolism and Immune Responses. Front Microbiol. 2017; 8. doi: 10.3389/fmicb.2017.01318

102. Pratt ZL, Kuzembayeva M, Sengupta S, Sugden B. The microRNAs of Epstein-Barr Virus are expressed at dramatically differing levels among cell lines. Virology. 2009; 386(2): 387-397. doi: 10.1016/j. virol.2009.01.006

103. Hassani A, Khan G. Epstein-Barr Virus and miRNAs: Partners in Crime in the Pathogenesis of Multiple Sclerosis? Front Immunol. 2019; 10. doi: 10.3389/fimmu.2019.00695

104. Vereide DT, Seto E, Chiu Y-F, et al. Epstein-Barr virus maintains lymphomas via its miRNAs. Oncogene. 2014; 33(10): 1258-1264. doi: 10.1038/onc. 2013.71

105. Fugl A, Andersen CL. Epstein-Barr virus and its association with disease - a review of relevance to general practice. BMC Fam Pract. 2019; 20(1): 62. doi: 10.1186/s12875-019-0954-3
106. Lung RW-M, Hau P-M, Yu KH-O, et al. EBV-encoded miRNAs target ATM-mediated response in nasopharyngeal carcinoma. J Pathol. 2018; 244(4): 394-407. doi: https://doi.org/10.1002/path.5018

107. Wan X-X, Yi H, Qu J-Q, He Q-Y, Xiao Z-Q. Integrated analysis of the differential cellular and EBV miRNA expression profiles in microdissected nasopharyngeal carcinoma and non-cancerous nasopharyngeal tissues. Oncol Rep. 2015; 34(5): 2585-2601. doi: 10.3892/or.2015.4237

108. Cai L, Ye Y, Jiang Q, et al. Epstein-Barr virus-encoded microRNA BART1 induces tumour metastasis by regulating PTEN-dependent pathways in nasopharyngeal carcinoma. Nat Commun. 2015; 6(1): 7353. doi: $10.1038 /$ ncomms8353

109. Chan JYW, Gao W, Ho WK, Wei WI, Wong TS. Overexpression of Epstein-Barr virus-encoded microRNA-BART7 in undifferentiated nasopharyngeal carcinoma. Anticancer Res. 2012; 32(8): 3201-3210.

110. Chen SJ, Chen GH, Chen YH, et al. Characterization of Epstein-Barr Virus miRNAome in Nasopharyngeal Carcinoma by Deep Sequencing. PLOS ONE. 2010; 5(9): e12745. doi: 10.1371/journal.pone.0012745 